\title{
Desregulated microRNAs in aging-related heart failure
}

\author{
Ran Zhuo ${ }^{1,2+}$, Siyi Fu ${ }^{1,2 \dagger}$, Shiyi $\mathrm{Li}^{1,2+}$, Mengchao Yao ${ }^{1,2}$, Dongchao Lv ${ }^{1,2}$, Tianzhao Xu ${ }^{1,2}$ and \\ Yihua Bei ${ }^{1,2,3}$ * \\ ${ }^{1}$ Regeneration Lab and Experimental Center of Life Sciences, School of Life Science, Shanghai University, Shanghai, China \\ 2 Shanghai Key Laboratory of Bio-Energy Crops, School of Life Science, Shanghai University, Shanghai, China \\ ${ }^{3}$ Innovative Drug Research Center of Shanghai University, Shanghai, China \\ ${ }^{*}$ Correspondence: beiyh36@gmail.com \\ ${ }^{\dagger}$ These authors have contributed equally to this work.
}

Edited by:

Joost Sluijter, University Medical Center Utrecht, Netherlands

Reviewed by:

Dandan Liang, Key Laboratory of Arrhythmias of the Ministry of Education of China, China

Keywords: microRNAs, cardiac aging, cardiac hypertrophy, cardiac remodeling, heart failure

Heart failure is the major cause of death in the western world. Despite the development and use of standard evidence-based therapeutic strategies for heart failure like inhibition of the activity of the $\beta$-adrenergic signaling and renin-angiotensin-aldosterone system, the prevalence of heart failure is still increasing, while morbidity and mortality have not been satisfactorily improved (Hofmann and Frantz, 2013). Growing evidence has indicated that the rising incidence of heart failure is substantially associated with age. In the United States, a high proportion of the estimated 5 million heart failure patients are older people, and a vast majority of heart failure-related hospitalization and death occurred in patients over 65 years old (Go et al., 2014). With the tendency of global aging, it is necessary to go deeper in exploring the aging-related heart failure.

Cardiac aging is characterized by a series of complex events of ventricle and valvular changes involving left ventricular hypertrophy, diastolic dysfunction, increased risk of atrial fibrillation, valvular degeneration and fibrosis, and decreased maximal exercise capacity. These changes make the aged heart more susceptible to stress, leading to a high prevalence of cardiovascular diseases and heart failure (Correia et al., 2002; Dai et al., 2012a). The mechanisms of progression to heart failure in the aged heart have been previously described. The oxidative stress and mitochondrial damage are responsible for triggering the increased cardiomyocyte death including necrosis, apoptosis and autophagy, accompanied by hypertrophy of remaining cells and impaired structure of extracellular matrix (ECM), thus leading to ventricular remodeling and reduced cardiac contractility (Nadal-Ginard et al., 2003; Sarkar et al., 2004; Lindsey et al., 2006; Dai et al., 2012b; Venkataraman et al., 2013). Meanwhile, cardiac hypertrophy leads to a mismatch in oxygen supply and demand, which contributes to endothelial dysfunction and angiogenesis (Shiojima et al., 2005; Izumiya et al., 2006; Heineke et al., 2007). In response to these chronic stress, the aged heart undergoes a complex pathophysiological changes and finally progresses to symptomatic heart failure (Foo et al., 2005; Dai et al., 2012a).

MicroRNAs (miRNAs, miRs) are a novel class of small non-coding RNAs with approximately 20-24 length of base, which function as endogenous suppressors of gene expression through mRNA degradation and/or translational inhibition mainly by binding to $3^{\prime}$-untranslated region $\left(3^{\prime}\right.$ UTR) of target mRNAs (Lim et al., 2005; Van Rooij, 2011). Nowadays over $2000 \mathrm{miR}$ NAs have been identified in human genome and each miRNA can modulate numerous target genes and build complex signaling networks (Kim and Nam, 2006; Liang, 2009). As a center player of gene regulation, many essential biological processes are regulated by miRNAs, including proliferation, apoptosis, necrosis, autophagy, differentiation, and stress responses (Bartel, 2004). Due to these multiple roles, miRNAs are critically involved in the development of multifarious heart diseases, such as heart hypertrophy, arrhythmia, acute myocardial infarction, and heart failure (Latronico and Condorelli, 2009; Xiao et al., 2012, 2014; Fu et al., 2013; Vickers et al., 2014). Several microarray studies have revealed expression profiles of specific miRNAs that are aberrantly expressed in heart failure. MiR-1, -29, -30, -133, and -150 were found to be downregulated in heart failure, whereas miR-21, -23 , $-27,-125,-132,-146,-195,-199,-214$, -223 , and 342 were upregulated (Van Rooij et al., 2006; Cheng et al., 2007; Ikeda et al., 2007; Sayed et al., 2007; Tatsuguchi et al., 2007; Thum et al., 2007; Sucharov et al., 2008; Matkovich et al., 2009; Naga Prasad et al., 2009). In addition, several circulating miRNAs including miR-423-5P have been considered as putative biomarkers for heart failure (Tijsen et al., 2010). Some distinguished reviews have summarized it in detail (Elzenaar et al., 2013; Kumarswamy and Thum, 2013; De Rosa et al., 2014; Harada et al., 2014).

As we know, cardiac aging is among the predominant risk factors for the development of heart failure (Correia et al., 2002; Dai et al., 2012a). Recent advances suggest that miRNAs may also play a role in the regulation of gene expression in cardiovascular aging processes (Zhang et al., 2012; Olivieri et al., 2013; Menghini et al., 2014). It has been previously demonstrated that 65 miRNAs were differentially expressed in the old versus young mouse adult hearts, approximately half of which belong to 11 miRNA clusters, indicating that these clusters contribute to the complex regulation of gene expression during heart aging (Zhang et al., 2012). 
In addition, miR-22 was shown to be involved in aging-related cardiac fibrosis, whose overexpression contributed to cellular senescence and migration of cardiac fibroblasts (Jazbutyte et al., 2013). More recently, it was demonstrated that aginginduced expression of miR-34a and inhibition of its target PNUTs lead to increased cardiomyocyte death and reduced cardiac contractility function, by inducing telomere shortening and DNA damage responses (Boon et al., 2013).

However, the role of miRNAs in agingrelated heart failure is far from elucidated. A previous study showed that the members of miR-17-92 cluster, including miR-18a, $-19 \mathrm{a}$, and $-19 \mathrm{~b}$, were all downregulated in failure-prone heart of aged mice as well as in cardiac biopsies of idiopathic cardiomyopathy patients at old age with severely impaired cardiac function (ejection fraction, $\mathrm{EF}<30 \%$ ), accompanied by increased expression of the ECM proteins connective tissue growth factor (CTGF) and thrombospondin-1 (TSP-1). Furthermore, the in vitro studies showed that these expression changes were specific in aged cardiomyocytes but not in cardiac fibroblasts, and the inhibition of miR-18/19 in cardiomyocytes contributed to collagen synthesis (Collagen 1A1 and 1A3) via the regulation of pro-fibrotic CTGF and TSP-1. Although the mechanisms underlying these regulations are still unknown, it provides a close relationship between miR18/19 and aging-induced cardiac remodeling and heart failure (Van Almen et al., 2011).

With the development of the research for roles of miRNAs in aging-related heart failure, its cellular and molecular mechanisms as well as pathophysiological changes will be further clarified, which will help develop novel miRNA-targeted therapeutic strategies for heart failure in aged people.

\section{ACKNOWLEDGMENTS}

This work was supported by the grants from Shanghai Undergraduate Training Programs for Innovation and Enterpreneurship (year 2013, to Siyi Fu, Mengchao Yao, and Ran Zhuo).

\section{REFERENCES}

Bartel, D. P. (2004). MicroRNAs: genomics, biogenesis, mechanism, and function. Cell 116, 281-297. doi: 10.1016/S0092-8674(04)00045-5
Boon, R. A., Iekushi, K., Lechner, S., Seeger, T., Fischer, A., Heydt, S., et al. (2013). MicroRNA-34a regulates cardiac ageing and function. Nature 495, 107-110. doi: 10.1038/nature11919

Cheng, Y., Ji, R., Yue, J., Yang, J., Liu, X., Chen, H., et al. (2007). MicroRNAs are aberrantly expressed in hypertrophic heart: do they play a role in cardiac hypertrophy? Am. J. Pathol. 170, 1831-1840. doi: 10.2353/ajpath.2007.061170

Correia, L. C. L., Lakatta, E. G., O’Connor, F. C., Becker, L. C., Clulow, J., Townsend, S., et al. (2002). Attenuated cardiovascular reserve during prolonged submaximal cycle exercise in healthy older subjects. J. Am. Coll. Cardiol. 40, 1290-1297. doi: 10.1016/S0735-1097(02)02132-0

Dai, D.-F., Chen, T., Johnson, S. C., Szeto, H., and Rabinovitch, P. S. (2012a). Cardiac aging: from molecular mechanisms to significance in human health and disease. Antioxid. Redox Signal. 16, 1492-1526. doi: 10.1089/ars.2011.4179

Dai, D.-F., Rabinovitch, P. S., and Ungvari, Z. (2012b). Mitochondria and cardiovascular aging. Circ. Res. 110, 1109-1124. doi: 10.1161/CIRCRESAHA.111. 246140

De Rosa, S., Curcio, A., and Indolfi, C. (2014) Emerging role of microRNAs in cardiovascular diseases. Circ. J. 78, 567-575. doi: 10.1253/circj.CJ14-0086

Elzenaar, I., Pinto, Y. M., and van Oort, R. J. (2013). MicroRNAs in heart failure: new targets in disease management. Clin. Pharmacol. Ther. 94, 480-489. doi: 10.1038/clpt.2013.138

Foo, R. S.-Y., Mani, K., and Kitsis, R. N. (2005). Death begets failure in the heart. J. Clin. Invest. 115 565-571. doi: 10.1172/JCI24569

Fu, S., Zhuo, R., Yao, M., Zhang, J., Zhou, H., and Xiao, J. (2013). MicroRNA basis of physiological hypertrophy. Front. Genet. 4:253. doi: 10.3389/fgene.2013.00253

Go, A. S., Mozaffarian, D., Roger, V. L., Benjamin, E. J., Berry, J. D., Blaha, M. J., et al. (2014). Executive summary: heart disease and stroke statisti cs22014 update: a report from the American Heart Association. Circulation 129, 399-410. doi: 10.1161/01.cir.0000442015.53336.12

Harada, M., Luo, X., Murohara, T., Yang, B., Dobrev, D., and Nattel, S. (2014). MicroRNA regulation and cardiac calcium signaling: role in cardiac disease and therapeutic potential. Circ. Res. 114, 689-705. doi: 10.1161/CIRCRESAHA.114.301798

Heineke, J., Auger-Messier, M., Xu, J., Oka, T., Sargent, M. A., York, A., et al. (2007). Cardiomyocyte GATA4 functions as a stress-responsive regulator of angiogenesis in the murine heart. J. Clin. Invest. 117, 3198-3210. doi: 10.1172/JCI32573

Hofmann, U., and Frantz, S. (2013). How can we cure a heart "in flame?" A translational view on inflammation in heart failure. Basic Res. Cardiol. 108, 356. doi: 10.1007/s00395-013-0356-y

Ikeda, S., Kong, S. W., Lu, J., Bisping, E., Zhang, H., Allen, P. D., et al. (2007). Altered microRNA expression in human heart disease. Physiol. Genomics 31, 367-373. doi: 10.1152/ physiolgenomics.00144.2007

Izumiya, Y., Shiojima, I., Sato, K., Sawyer, D. B., Colucci, W. S., and Walsh, K. (2006). Vascular endothelial growth factor blockade promotes the transition from compensatory cardiac hypertrophy to failure in response to pressure overload. Hypertension 47, 887-893. doi: 10.1161/01.HYP.0000215207.54689.31

Jazbutyte, V., Fiedler, J., Kneitz, S., Galuppo, P., Just, A., Holzmann, A., et al. (2013). MicroRNA-22 increases senescence and activates cardiac fibroblasts in the aging heart. Age 35, 747-762. doi: 10.1007/s11357-012-9407-9

Kim, V. N., and Nam, J.-W. (2006). Genomics of microRNA. Trends Genet. TIG 22, 165-173 doi: 10.1016/j.tig.2006.01.003

Kumarswamy, R., and Thum, T. (2013). Noncoding RNAs in cardiac remodeling and heart failure. Circ. Res. 113, 676-689. doi: 10.1161/CIRCRESAHA.113.300226

Latronico, M. V. G., and Condorelli, G. (2009). MicroRNAs and cardiac pathology. Nat. Rev Cardiol. 6, 419-429. doi: 10.1038/nrcardio.2009.56

Liang, M. (2009). MicroRNA: a new entrance to the broad paradigm of systems molecular medicine. Physiol. Genomics 38, 113-115. doi: 10.1152/physiolgenomics.00080.2009

Lim, L. P., Lau, N. C., Garrett-Engele, P., Grimson, A., Schelter, J. M., Castle, J., et al. (2005). Microarray analysis shows that some microRNAs downregulate large numbers of target mRNAs. Nature 433, 769-773. doi: 10.1038/nature03315

Lindsey, M. L., Escobar, G. P., Dobrucki, L. W., Goshorn, D. K., Bouges, S., Mingoia, J. T., et al. (2006). Matrix metalloproteinase-9 gene deletion facilitates angiogenesis after myocardial infarction. Am. J. Physiol. Heart Circ. Physiol. 290, H232-H239. doi: 10.1152/ajpheart.00457.2005

Matkovich, S. J., Van Booven, D. J., Youker, K. A., Torre-Amione, G., Diwan, A., Eschenbacher, W. H., et al. (2009). Reciprocal regulation of myocardial microRNAs and messenger RNA in human cardiomyopathy and reversal of the microRNA signature by biomechanical support. Circulation 119, 1263-1271. doi: 10.1161/CIRCULATIONAHA.108.813576

Menghini, R., Stöhr, R., and Federici, M. (2014). MicroRNAs in vascular aging and atherosclerosis. Ageing Res. Rev. doi: 10.1016/j.arr.2014.03.005. [Epub ahead of print].

Nadal-Ginard, B., Kajstura, J., Leri, A., and Anversa, P. (2003). Myocyte death, growth, and regeneration in cardiac hypertrophy and failure. Circ. Res. 92, 139-150. doi: 10.1161/01.RES.0000053618.86362.DF

Naga Prasad, S. V., Duan, Z.-H., Gupta, M. K., Surampudi, V. S. K., Volinia, S., Calin, G. A., et al. (2009). Unique microRNA profile in end-stage heart failure indicates alterations in specific cardiovascular signaling networks. J. Biol. Chem. 284, 27487-27499. doi: 10.1074/jbc.M109.036541

Olivieri, F., Lazzarini, R., Recchioni, R., Marcheselli, F., Rippo, M. R., Di Nuzzo, S., et al. (2013). MiR-146a as marker of senescence-associated pro-inflammatory status in cells involved in vascular remodelling. Age 35, 1157-1172. doi: 10.1007/s11357-012-9440-8

Sarkar, S., Chawla-Sarkar, M., Young, D., Nishiyama, K., Rayborn, M. E., Hollyfield, J. G., et al (2004). Myocardial cell death and regeneration during progression of cardiac hypertrophy to heart failure. J. Biol. Chem. 279, 52630-52642. doi: 10.1074/jbc.M402037200

Sayed, D., Hong, C., Chen, I.-Y., Lypowy, J., and Abdellatif, M. (2007). MicroRNAs play an 
essential role in the development of cardiac hypertrophy. Circ. Res. 100, 416-424. doi: 10.1161/01.RES.0000257913.42552.23

Shiojima, I., Sato, K., Izumiya, Y., Schiekofer, S., Ito, M., Liao, R., et al. (2005). Disruption of coordinated cardiac hypertrophy and angiogenesis contributes to the transition to heart failure. J. Clin. Invest. 115, 2108-2118. doi: 10.1172/JCI24682

Sucharov, C., Bristow, M. R., and Port, J. D. (2008). miRNA expression in the failing human heart: functional correlates. J. Mol. Cell. Cardiol. 45, 185-192. doi: 10.1016/j.yjmcc.2008.04.014

Tatsuguchi, M., Seok, H. Y., Callis, T. E., Thomson, J. M., Chen, J.-F., Newman, M., et al. (2007). Expression of microRNAs is dynamically regulated during cardiomyocyte hypertrophy. J. Mol. Cell. Cardiol. 42, 1137-1141. doi: 10.1016/j.yjmcc.2007.04.004

Thum, T., Galuppo, P., Wolf, C., Fiedler, J., Kneitz, S., van Laake, L. W., et al. (2007). MicroRNAs in the human heart: a clue to fetal gene reprogramming in heart failure. Circulation 116, 258-267. doi: 10.1161/CIRCULATIONAHA.107.687947

Tijsen, A. J., Creemers, E. E., Moerland, P. D., de Windt, L. J., van der Wal, A. C., Kok, W. E., et al. (2010). MiR423-5p as a circulating biomarker for heart failure. Circ. Res. 106, 1035-1039. doi: 10.1161/CIRCRESAHA.110.218297

Van Almen, G. C., Verhesen, W., van Leeuwen, R. E. W., van de Vrie, M., Eurlings, C., Schellings,
M. W. M., et al. (2011). MicroRNA-18 and microRNA-19 regulate CTGF and TSP-1 expression in age-related heart failure. Aging Cell 10, 769-779. doi: 10.1111/j.1474-9726.2011. 00714.x

Van Rooij, E. (2011). The art of microRNA research. Circ. Res. 108, 219-234. doi: 10.1161/CIRCRESAHA.110.227496

Van Rooij, E., Sutherland, L. B., Liu, N., Williams, A. H., McAnally, J., Gerard, R. D., et al. (2006). A signature pattern of stress-responsive microRNAs that can evoke cardiac hypertrophy and heart failure. Proc. Natl. Acad. Sci. U.S.A. 103, 18255-18260. doi: 10.1073/pnas.0608791103

Venkataraman, K., Khurana, S., and Tai, T. C. (2013). Oxidative stress in aging-matters of the heart and mind. Int. J. Mol. Sci. 14, 17897-17925. doi: 10.3390/ijms140917897

Vickers, K. C., Rye, K.-A., and Tabet, F. (2014). MicroRNAs in the onset and development of cardiovascular disease. Clin. Sci. 126, 183-194. doi: 10.1042/CS20130203

Xiao, J., Liang, D., Zhang, H., Liu, Y., Zhang, D., Liu, Y., et al. (2012). MicroRNA-204 is required for differentiation of human-derived cardiomyocyte progenitor cells. J. Mol. Cell. Cardiol. 53, 751-759. doi: 10.1016/j.yjmcc.2012. 08.024

Xiao, J., Shen, B., Li, J., Lv, D., Zhao, Y., Wang, F., et al. (2014). Serum microRNA-499 and
microRNA-208a as biomarkers of acute myocardial infarction. Int. J. Clin. Exp. Med. 7, 136-141.

Zhang, X., Azhar, G., and Wei, J. Y. (2012). The expression of microRNA and microRNA clusters in the aging heart. PLoS ONE 7:e34688. doi: 10.1371/journal.pone.0034688

Conflict of Interest Statement: The authors declare that the research was conducted in the absence of any commercial or financial relationships that could be construed as a potential conflict of interest.

Received: 05 May 2014; accepted: 02 June 2014; published online: 25 June 2014.

Citation: Zhuo R, Fu S, Li S, Yao M, Lv D, Xu T and Bei $Y$ (2014) Desregulated microRNAs in aging-related heart failure. Front. Genet. 5:186. doi: 10.3389/fgene. 2014.00186

This article was submitted to Epigenomics and Epigenetics, a section of the journal Frontiers in Genetics.

Copyright (c) $2014 \mathrm{Zhuo,} F u, \mathrm{Li}, \mathrm{Yao}, \mathrm{Lv}, \mathrm{Xu}$ and Bei. This is an open-access article distributed under the terms of the Creative Commons Attribution License (CC BY). The use, distribution or reproduction in other forums is permitted, provided the original author(s) or licensor are credited and that the original publication in this journal is cited, in accordance with accepted academic practice. No use, distribution or reproduction is permitted which does not comply with these terms. 